\title{
Spectrum of interstitial lung diseases and their association with pulmonary hypertension
}

\author{
Richa Tyagi ${ }^{1}$, Surya Kant ${ }^{1}$, Sanjeev Kumar Verma ${ }^{1}$, Ram Awadh Singh Kushwaha ${ }^{1}$, Santosh Kumar ${ }^{1}$, \\ Rajiv Garg ${ }^{1}$, Ajay Kumar Verma ${ }^{1}$, Anand Srivastava ${ }^{1}$, Darshan Kumar Bajaj ${ }^{1}$, Anupam Wakhlu ${ }^{2}$, \\ Anit Parihar ${ }^{3}$, Akshyaya Pradhan ${ }^{4}$, Riddhi Jaiswal ${ }^{5}$ \\ ${ }^{1}$ Department of Respiratory Medicine; ${ }^{2}$ Department of Clinical Immunology and Rheumatology; ${ }^{3}$ Department of \\ Radiodiagnosis; ${ }^{4}$ Department of Cardiology; ${ }^{5}$ Department of Pathology, King George's Medical University, Lucknow, \\ India
}

\begin{abstract}
Interstitial lung diseases (ILDs) are an intriguing group of pulmonary disorders, which still require the study of epidemiological,
\end{abstract}

Correspondence: Dr. Surya Kant, Department of Respiratory

Medicine, King George's Medical University, Lucknow 226003, Uttar Pradesh, India.

Tel. +91.9415016858

E-mail: suryakant@kgmcindia.edu

Keywords: Diffuse parenchymal lung disease; interstitial lung disease; chronic lung disease; pulmonary circulation; prevalence of pulmonary hypertension.

Contributions: RT, SK, study concept, literature search, guarantors; SK, AW, APa, AP, RJ, definition of intellectual content; RT, SK, AW, AP, statistical analysis; RT, AW, manuscript drafting; SK, AW, AP, manuscript review and editing; all authors, study design, data acquisition. All the authors have read and approved the final version of the manuscript and agreed to be accountable for all aspects of the work.

Conflict of interest: The authors declare that they have no competing interests, and all authors confirm accuracy.

Ethics approval and consent to participate: Approval to conduct the study was obtained from Institutional Ethics Committee of the King George's Medical University, Lucknow, India. Informed, written consent was obtained from all subjects before inclusion into the study.

Received for publication: 23 July 2021.

Accepted for publication: 6 October 2021.

Publisher's note: All claims expressed in this article are solely those of the authors and do not necessarily represent those of their affiliated organizations, or those of the publisher, the editors and the reviewers. Any product that may be evaluated in this article or claim that may be made by its manufacturer is not guaranteed or endorsed by the publisher.

${ }^{\circ}$ Copyright: the Author(s), 2021

Licensee PAGEPress, Italy

Monaldi Archives for Chest Disease 2022; 92:2027

doi: 10.4081/monaldi.2021.2027

This article is distributed under the terms of the Creative Commons Attribution-NonCommercial International License (CC BY-NC 4.0) which permits any noncommercial use, distribution, and reproduction in any medium, provided the original author(s) and source are credited. genetic, pathophysiological, clinical, and radiological parameters. Pulmonary hypertension $(\mathrm{PH})$ is an underreported complication in interstitial lung diseases which is associated with worse outcome. In our study, we have reported the spectrum of ILDs and estimated the prevalence of pulmonary hypertension among these subjects at a tertiary care center. A cross-sectional study was performed in which demographical, clinical, radiological, and histological data of subjects with ILD, attending the Department of Respiratory Medicine in the University was collected from $1^{\text {st }}$ September 2018 to $31^{\text {st }}$ August 2019. Serological tests were done wherever indicated. Standard criteria along with multidisciplinary opinion were needed to arrive at the final diagnosis. All subjects were screened for pulmonary hypertension via 2-D echocardiography. Mean pulmonary artery pressure $\geq 20 \mathrm{mmHg}$ was used to define $\mathrm{PH}$. In the defined period, 239 subjects were enrolled ( $58 \%$ females, $n=141$; mean age $52.38 \pm 13.40$ years). A tissue diagnosis was obtained in $34 \%$ cases. The most common ILD was hypersensitivity pneumonitis $(32.2 \%)$, followed by autoimmune-ILD (31.4\%), idiopathic pulmonary fibrosis (IPF) (15.9\%) and sarcoidosis (12.6\%), non-IPF idiopathic interstitial pneumonitis $(2.1 \%)$ and rest 21 $(5.9 \%)$ subjects were diagnosed as other types of ILD. Pulmonary hypertension was seen in $46.0 \%$ of subjects.

\section{Introduction}

Interstitial lung diseases (ILDs) are a group of disorders that have been grouped together owing to common clinical, radiological and pathological features [1-6]. Apart from the interstitium, the airways, alveoli, blood vessels also get involved. The exact pathogenetic mechanisms have not been understood for most of the ILDs. Numerous studies were done over decades and gradually, association has been established with respect to demographical, clinical, radiological and histopathological parameters, association with different kinds of exposures, genetic factors, ethnicity and geographical factors. This has led to a significant improvement in the understanding of ILDs. Various attempts have been made to classify these from time to time. An etiological classification was given by American Thoracic Society (ATS), which was later revised by classifying IIPs as major, rare, and unclassifiable. The latest classification proposed by Cottin et al. classifies ILDs depending upon their course of fibrosis [7]. This certainly is a step in the direction of early prognostication of subjects. In India, with improved understanding of ILDs, the first guideline for the management of ILDs was released recently [8]. While common fea- 
tures group them together, the heterogeneity of the epidemiological parameters requires more data to add to our knowledge.

As far as the course is concerned, most of the ILDs are progressive despite therapy and are not associated with a good outcome. Pulmonary hypertension is a dreaded complication that may develop secondary to hypoxia induced changes in the vessel walls or due to involvement of the pulmonary vasculature per se. A variable prevalence of pulmonary hypertension has been seen among ILD subjects worldwide [9-14]. It further adds to the symptoms, functional impairment, morbidity, and mortality in these subjects $[13,14]$. Unfortunately, it is an underrecognized complication due to the subtle presentation that may be attributed to the ILD itself. This delays the diagnosis and the patient develops right heart failure.

Pulmonary hypertension is defined as mean pulmonary artery pressure $(\mathrm{mPAP}) \geq 25 \mathrm{~mm} \mathrm{Hg}$ at rest with $>3$ Woods unit peripheral vascular resistance measured by right heart catheterization [15]. The importance of early diagnosis of pulmonary hypertension was distinctly highlighted at the $6^{\text {th }}$ World Pulmonary Hypertension Symposium where the cut-off value of mPAP was lowered to $\geq 20$ $\mathrm{mmHg}$ [16]. Right heart catheterization is the gold standard investigation, however, owing to its noninvasive nature and low cost, the most common tool employed to assess pulmonary hemodynamics is transthoracic echocardiography [17-19].

In the present study, we have studied the spectrum of ILDs and screened the subjects for $\mathrm{PH}$ and reported the prevalence at a tertiary care center in Northern India.

\section{Materials and Methods}

This was a cross-sectional study conducted in the Department of Respiratory Medicine, King George's Medical University, Lucknow, India, over a period of one year (from $1^{\text {st }}$ September, 2018 to $31^{\text {st }}$ August, 2019). Consecutive subjects who fulfilled the following inclusion criteria were enrolled: i) age greater than 12 years; (i) subjects presenting with dry cough, shortness of breath on exertion, or other unexplained respiratory symptoms and highresolution computed tomography (HRCT) of the thorax suggestive of ILD. Informed, written consent was obtained from all subjects before inclusion into the study and approval to conduct the study was obtained from Institutional Ethics Committee. Subjects who did not provide consent, those with purely obstructive airway disease, or suspected recent or active infection (tubercular or other bacterial) or malignancy were excluded.

A detailed comprehensive history including age, gender, residence, occupation, exposure, smoking history, symptoms related to connective tissue diseases like joint pain, rash, fever, hemoptysis, dry eyes, dry mouth, gastric reflux and history of drugs (including anti-tuberculosis treatment) and radiation exposure were taken. A thorough general physical and systemic examination was performed. Socioeconomic status was defined using the modified Kuppuswamy scale [20]. Modified medical research council (mMRC) dyspnea scale was used to assess the severity of breathlessness [21]. The 6-minute walk test was performed in a closed corridor in the department as per the latest ATS criteria, with verbal instructions in native language every minute [22]. Spirometry with transfer factor of lungs for carbon monoxide (TLCO) was performed for all the willing/compliant subjects who could follow the instructions and interpreted using the standard guidelines [23-26].

Bronchoscopy was done wherever indicated and the patient provided consent for the procedure. Bronchoalveolar lavage fluid was collected for cytological study and trans-bronchial needle aspiration (TBNA) and trans-bronchial lung biopsy (TBLB) were taken wherever possible and indicated to establish the histopathological diagnosis. Fine needle aspiration cytology (FNAC) was done from peripheral lymphadenopathy or any other lesion in suspected sarcoidosis cases. HRCT patterns were grouped according to the American Thoracic Society/European Respiratory Society (ERS)/Japanese Respiratory Society (JRS)/Latin American Thoracic Association (ALAT) guideline 2018, wherein the predominant pattern was identified as Usual interstitial pneumonia (UIP), probable UIP, indeterminate for UIP, alternate diagnosis and non-specific interstitial pneumonia (NSIP) in consultation with the same radiologist, to minimize inter-observer variability [27].

\section{Diagnosis of ILD}

Idiopathic pulmonary fibrosis (IPF) was diagnosed following ATS/ERS/JRS/ALAT Clinical Practice guideline 2018 and ATS/ERS Multidisciplinary Consensus Classification of Idiopathic Interstitial Pneumonia (IIP) was followed for diagnosis of non-IPF IIPs [27,28]. Hypersensitivity pneumonitis was diagnosed when a history of exposure was present, along with classic HRCT findings like ground-glass opacities, mosaic attenuation, centrilobular nodules, septal thickening, honeycombing or with a tissue diagnosis if possible. Sarcoidosis was diagnosed by the presence of non-caseating granulomas in TBNA or FNAC from an accessible site. An elevated serum angiotensin-converting enzyme (ACE) level and 24hour urinary calcium supported the diagnosis. Rheumatology opinion was sought in suspected autoimmune-ILD cases and wherever indicated, relevant serological and autoimmune investigations were done. Idiopathic pulmonary fibrosis with autoimmune features (IPAF) was diagnosed using standard guideline [29].

Transthoracic 2-Dimensional echocardiography was done for all the subjects by the same cardiologist and the relevant parameters were noted. Pulmonary hypertension was defined as mPAP $\geq 20 \mathrm{mmHg}$ at rest [16]. Right atrial (RA) enlargement was said to occur when RA area $>18 \mathrm{~cm}^{2}$. Tricuspid annular plane systolic excursion (TAPSE) indicated the longitudinal function of right ventricle. Its normal value was $>1.6$ [30]. Mean pulmonary artery pressure was calculated using Mahan's equation: $\mathrm{mPAP}=79$ $\left(0.45^{*} \mathrm{PAT}\right)$ where PAT is pulmonary acceleration time [31]. Right ventricular systolic pressure was calculated using tricuspid regurgitation (TR) velocity as $\mathrm{RVSP}=4 \mathrm{~V}^{2}+\mathrm{RA}$ pressure where $\mathrm{V}$ is the TR velocity. It was then utilized to grade severity as mild, moderate and severe: mPAP between $20-40 \mathrm{mmHg}, 41-55 \mathrm{mmHg}$ and $>55 \mathrm{mmHg}$ respectively [32]. On chest radiograph, right pulmonary artery was considered enlarged if the diameter exceeded $16 \mathrm{~mm}$ at the level of its bifurcation.

Sample size was calculated using the formula $n=Z^{2}(P Q) / e^{2}$ where $n=$ sample size, $\mathrm{Z}=$ value of the standard normal deviate at two sided $95 \%$ confidence level $=1.96, p=$ prevalence $(=2), q=1-p$, $\mathrm{e}=$ allowable error in the sample estimate/ level of precision $(=2)$. Utilizing the prevalence (2\%) derived from ILD India Registry [33], the calculated sample size was 188 . However, a larger number of subjects attended the department and 239 subjects who gave written informed consent and fulfilled the following criteria were recruited. The statistical analysis was done using SPSS (Statistical Package for Social Sciences) version 21.0 statistical analysis software. The values were represented in Number (\%) and mean \pm SD. Chi-square test $\left(\mathrm{c}^{2}\right)$ was used to compare categorical data. Analysis of variance (ANOVA) was used to compare the within group and between group variances amongst the study groups. Kruskall 
Wallis H Test was used to determine significant difference between two or more groups of an independent variable. Level of significance: $\mathrm{p}<0.05$ was considered significant.

\section{Results}

The baseline characteristics of the subjects are tabulated in Table 1. Out of 239 subjects enrolled in the study, 141 (59.0\%) were females, rest males. There was a slight preponderance of enrolled subjects from rural areas $(n=136 ; 56.9 \%)$. Most had breathlessness of mMRC grade 2. Out of 239 subjects, only 220 were able to complete 6-minute walk test with a mean distance of 94.4 meters. $10 \%$ subjects could not perform spirometry with TLCO, either because of dyspnea or procedural difficulties. In those able to perform, a restrictive pattern was seen in $74.9 \%$ and $88.3 \%$ had diffusion defect. The mean pulmonary artery pressure of the study population was $22.3 \mathrm{mmHg}$. The most common ILD seen was hypersensitivity pneumonitis (HP) (32.2\%), closely followed by autoimmune-ILD (31.4\%), remaining were diagnosed as IPF, non-IPF IIPs, sarcoidosis and other types of interstitial lung diseases (Table 2, Figure 1). ILDs related to bird exposure constituted nearly one third of the HP cases. Among autoimmune-ILD,

Table 1. Baseline characteristics of the study population $(n=239)$.

\begin{tabular}{|c|c|}
\hline Characteristics & Statistics \\
\hline Mean age \pm SD (range) & $52.4 \pm 13.4(15-88)$ \\
\hline $\begin{array}{l}\text { Gender } \\
\text { Female } \\
\text { Male }\end{array}$ & $\begin{array}{c}141(59.0 \%) \\
98(41.0 \%)\end{array}$ \\
\hline $\begin{array}{l}\text { Residence } \\
\text { Rural } \\
\text { Semi-urban } \\
\text { Urban }\end{array}$ & $\begin{array}{c}136(56.9 \%) \\
2(0.8 \%) \\
101(42.3 \%)\end{array}$ \\
\hline $\begin{array}{l}\text { Occupation } \\
\text { Farmer } \\
\text { Homemaker } \\
\text { Office work } \\
\text { Outdoor } \\
\text { Chemical/Dust exposure } \\
\text { Student/None }\end{array}$ & $\begin{array}{l}34(14.2 \%) \\
131(54.8 \%) \\
36(15.1 \%) \\
11(4.6 \%) \\
21(8.8 \%)\end{array}$ \\
\hline Smokers/ ex-smokers & $51(21.3 \%)$ \\
\hline $\mathrm{H} / \mathrm{o}$ ATT & $49(20.5 \%)$ \\
\hline $\begin{array}{l}\text { Spirometry finding } \\
\text { Could not perform } \\
\text { Mean FVC }(n=215) \\
\text { Mean FVC \%predicted }(n=215) \\
\text { Mean TLCO }(n=215)\end{array}$ & $\begin{array}{c}24(10.0 \%) \\
1.8 \pm 0.6(0.50-3.52) \\
60.8 \pm 15.1(22-115 \%) \\
45.0 \pm 13.7(16-94)\end{array}$ \\
\hline Mean $\mathrm{SpO}_{2} \pm \mathrm{SD}$ & $94.4 \pm 4.9(67-100 \%)$ \\
\hline Median mMRC (range; mean \pm SD) & $2.00(0-4 ; 2.2 \pm 0.9)$ \\
\hline Mean 6 MWD $(n=220)$ & $275.5 \pm 97.1(30-570)$ \\
\hline $\mathrm{mPAP} \pm \mathrm{SD}($ range $)$ & $22.3 \pm 10.1(8-61)$ \\
\hline Mean pulmonary artery diameter \pm SD (range) & $27.4 \pm 3.4(22-40)$ \\
\hline
\end{tabular}

nearly half of the cases were of RA-ILD (rheumatoid arthritisILD) (48\%), followed by SSc-ILD (systemic sclerosis/scleroderma-ILD) $(21.3 \%)$. There was a lower lobe predominance on HRCT thorax (43.9\%) (Table 1). Most common finding was septal thickening $(79.0 \%)$ followed by traction bronchiectasis $(38.5 \%)$ (Table 3). Some characteristic HRCT thorax findings are shown in Figure 2. Tissue diagnosis was possible in only 82 subjects (34.3\%). The final diagnosis was made after a muti-disciplinary discussion and consensus. The mean duration of illness at the time of presentation was maximum for autoimmune-ILD (mean 4.9 years) and minimum for IPF (mean 1.9 years). Nearly a quarter of HP and sarcoidosis subjects received anti-tuberculosis therapy (ATT) from outside before getting diagnosed at our center (Table 4). The most common presenting symptom was dyspnea that was seen in $93.3 \%$ of subjects followed by dry cough in $77.4 \%$. The most consistent examination finding were crepts on auscultation in $87.45 \%$. Clubbing was seen in $40 \%$. Features of pulmonary hypertension like raised jugular venous pressure and right heart failure were present in a small number (about 15\%). Pulmonary hypertension defined as $\mathrm{mPAP} \geq 20 \mathrm{mmHg}$ was present in nearly half of the subjects $(46.0 \%)$. The largest number of pulmonary hypertension subjects were those with hypersensitivity pneumonitis due to its highest prevalence. When diagnosis wise prevalence was seen, most of the cases categorized among other interstitial diseases had the highest prevalence (Table 5). Most had mild to moderate grade severity. As there were only 2 severe cases, for further statistical analysis, moderate and severe cases were combined together. The echocardiography findings such as tricuspid regurgitation velocity, right atrial and ventricular enlargement were significantly noted only in moderate and severe cases $(p<0.001)$ The different echocardiography, chest radiograph and ECG findings in relation with presence of pulmonary hypertension are summarized in Table 6. There was a decline in diffusion capacity of the lungs in subjects with $\mathrm{PH}$, though the value was non-significant ( $\mathrm{p}=0.172$ ).

\section{Discussion}

The present cross-sectional study found that the most common ILDs at our tertiary care centre are hypersensitivity pneumonitis $(32.2 \%)$ and autoimmune ILDs (31.4\%) with a high prevalence of pulmonary hypertension $(46.0 \%)$.

A wide range of variation exists in the clinical and demographic profile of ILDs worldwide. While western countries have reported a prevalence close to 30 per 100,000 population, with higher proportion of IPF and sarcoidosis cases, the largest Indian

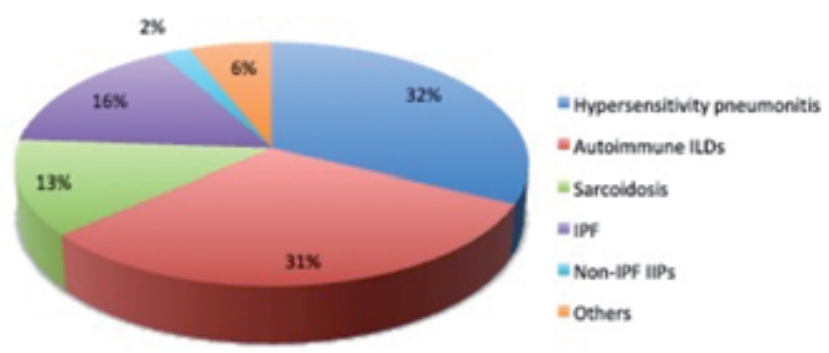

Figure 1. Distribution of study population according to diagnosis. 
Table 2. Distribution according to final diagnosis (including sub-categories).

1- $\quad$ Hypersensitivity pneumonitis $(\mathrm{n}=77)$

$\begin{array}{lcc}\text { Pigeon breeder's lung } & 10 & 13.0 \\ \text { Chicken breeder's lung } & 5 & 6.5 \\ \text { Bird Fancier's lung } & 10 & 13.0 \\ \text { Farmer's lung } & 9 & 11.7 \\ \text { Miller's lung } & 3 & 3.9 \\ \text { Bagassosis } & 1 & 1.3 \\ \text { Others } & 39 & 50.6\end{array}$

\begin{tabular}{|c|c|c|c|}
\hline $2-$ & $\begin{array}{l}\text { Autoimmune ILDs }(\mathrm{n}=75) \\
\text { RA } \\
\text { SSc } \\
\text { LSc } \\
\text { IPAF } \\
\text { Antisynthetase syndrome } \\
\text { JIA } \\
\text { RA/SSc overlap } \\
\text { SLE }\end{array}$ & $\begin{array}{l}36 \\
16 \\
7 \\
7 \\
2 \\
1 \\
2 \\
4\end{array}$ & $\begin{array}{c}48.0 \\
21.3 \\
9.3 \\
9.3 \\
2.7 \\
1.3 \\
2.7 \\
5.3\end{array}$ \\
\hline $3-$ & $\begin{array}{l}\text { Sarcoidosis }(\mathrm{n}=30) \\
\text { Stage I } \\
\text { Stage II } \\
\text { Stage III } \\
\text { Stage IV }\end{array}$ & $\begin{array}{c}12 \\
9 \\
1 \\
8\end{array}$ & $\begin{array}{c}40.0 \\
30.0 \\
3.3 \\
26.7\end{array}$ \\
\hline $4-$ & IPF $(\mathrm{n}=38)$ & 38 & 100.0 \\
\hline $5-$ & $\begin{array}{l}\text { Non-IPF IIPs }(\mathrm{n}=5) \\
\text { iNSIP } \\
\text { RBILD } \\
\text { COP }\end{array}$ & $\begin{array}{l}2 \\
1 \\
2\end{array}$ & $\begin{array}{l}40.0 \\
20.0 \\
40.0\end{array}$ \\
\hline 6. & $\begin{array}{l}\text { Others }(\mathrm{n}=14) \\
\text { CPFE } \\
\text { LCH } \\
\text { Radiation induced } \\
\text { Occupational (silicosis) } \\
\text { Occupational (Welder's lung) } \\
\text { Undiagnosed }\end{array}$ & $\begin{array}{l}2 \\
3 \\
1 \\
5 \\
2 \\
1\end{array}$ & $\begin{array}{c}14.3 \\
21.4 \\
7.1 \\
35.7 \\
14.3 \\
7.1\end{array}$ \\
\hline
\end{tabular}

ILD, interstitial lung disease; RA, rheumatoid arthritis; SSc, systemic sclerosis; LSc, localized scleroderma; IPAF, interstitial pneumonia with autoimmune features; JIA, juvenile idiopathic arthritis; SLE, systemic lupus erythematosus; IPF, idiopathic pulmonary fibrosis; iNSIP, idiopathic non-specific interstitial pneumonitis; RBILD, respiratory bronchiolitis-interstitial lung disease; COP, cryptogenic organizing pneumonia; CPFE, combined pulmonary fibrosis and emphysema; LCH, Langerhans cell histiocytosis.

Table 3. HRCT thorax abnormalities.

\begin{tabular}{lcc} 
HRCT characteristics & Total $(\mathbf{n = 2 3 9 )}$ & \\
Predominant distribution & \multicolumn{2}{c}{ Percentage } \\
Upper/middle & 43.918 .8 & \\
Lower 105 & 45 & \\
Uniform & & \\
Findings & 189 & 79.07 \\
Septal thickening & 92 & 38.49 \\
Traction bronchiectasis & 33.05 & 23.84 \\
GGO 79 & 57 & 19.25 \\
Honeycombing & 46 & 16.32 \\
Nodules & 39 & \\
Mediastinal LN & 14.64 & 5.43 \\
Mosaic 35 & 13 & 4.60 \\
PBV thickening & 11 & \\
Dilated esophagus & 4.18 & 0.84 \\
Cysts 10 & 2 & 0.83 \\
Pleural plaques & 2 & 0.84 \\
Consolidation & 2 & \\
Emphysematous bullae & & \\
\hline
\end{tabular}

HRCT, high resolution computed tomography; GGO, ground glass opacities; PBV, peri-bronchovascular. 
study published in 2015, had different results and reported the highest prevalence to be that of hypersensitivity pneumonitis [33]. Another important study by Dhooria et al. had sarcoidosis as the commonest ILD at their centre [34]. Indeed, the pattern can certainly vary, as there are different exposures, climatic conditions, genetic predisposition and pattern of referral. Our ILD prevalence patterns are in concordance with this ILD India Registry. Comparison with other recent studies (studies done in last 10 years) is tabulated in Table 7 . About $57 \%$ of the subjects were recruited from rural areas. It was a limitation admitted in ILD India registry that they were not able to recruit subjects from rural population. Dhooria et al. reported $27.5 \%$ of their subjects from rural region, while $72.5 \%$ from urban areas [34]. The most common occupation was homemaker $(54.8 \%)$, which is likely as there was a modest dominance of female subjects and rural residence. This is a confounding factor in our study. Our department is a tertiary care centre, which caters to the needs of population from
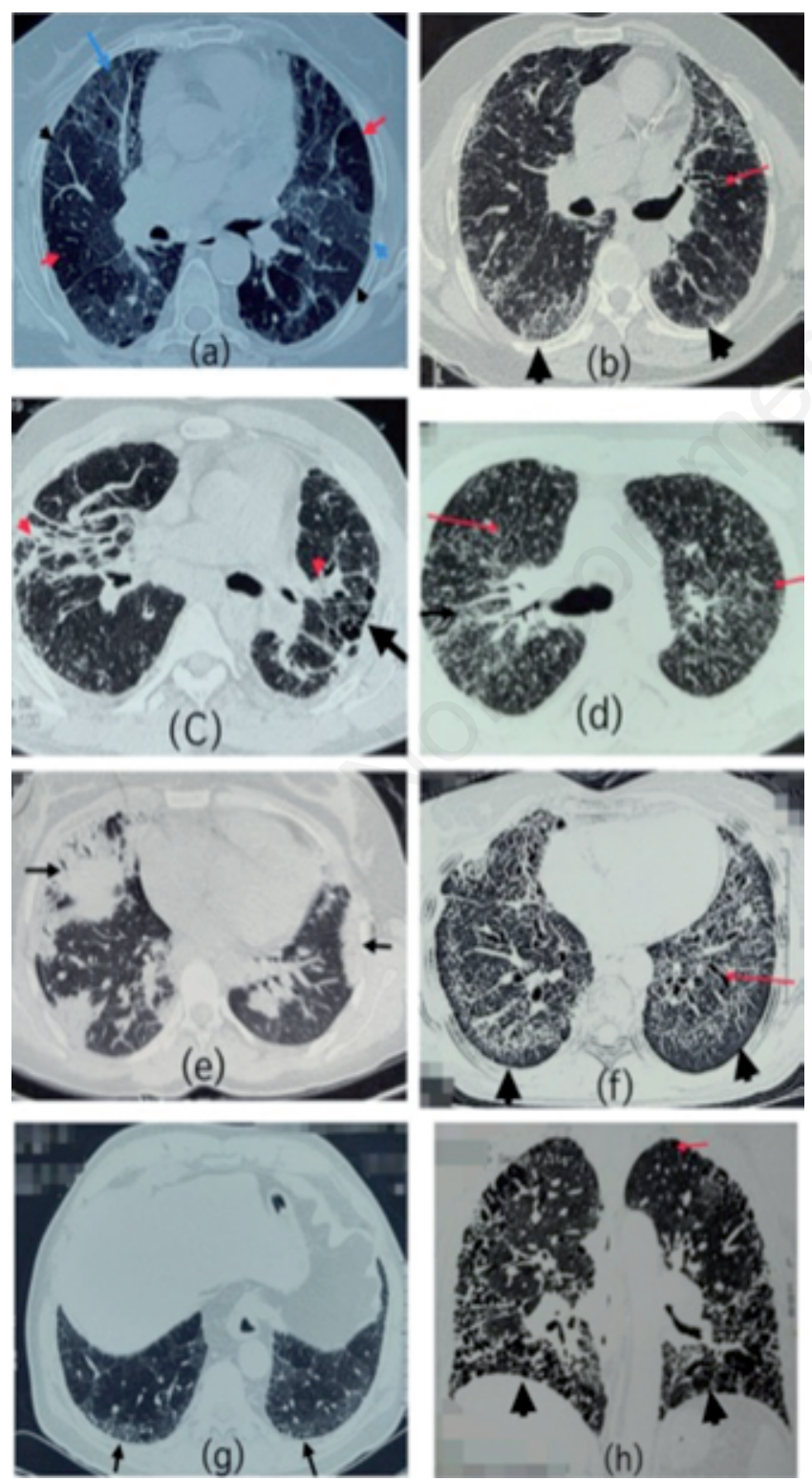

northern and eastern Indian states. The people in these regions frequently breed pigeons, hens and cattle, which could account for a high percentage of hypersensitivity pneumonitis cases. Cytopathological or histopathological diagnosis could be achieved in 82 subjects (34.3\%). The rest either did not consent for the procedure or were unfit to undergo the procedure or had an inconclusive report or the procedure was not indicated (clear UIP pattern). The importance of multidisciplinary consultation and discussion is well recognized in the diagnosis of ILDs and we utilized the same. It is indeed worrisome that ILD is still misdiagnosed as pulmonary tuberculosis in India and nearly $25 \%$ subjects received ATT before reporting to us. As most of the peripheral health practioners in India still lack knowledge about ILDs, they often prescribe ATT to patients with chronic cough and infiltrates on chest radiograph as tuberculosis is endemic in the country. Lack of facility for HRCT thorax and serological investigations in peripheral areas is also a contributing factor in misdiagnosis. These patients are referred to tertiary centers when there is no relief after several weeks of ATT. This has been reported by other studies in India and neighbouring countries as well [33-35]. This certainly calls for more vigorous sensitization about ILDs in peripheries in a developing country like India.

The symptom profile overlaps in ILDs and PH. The most common clinical features dyspnea, cough and crepts are common to both. Specific features of PH like chest pain, elevated jugular venous pressure or loud P2 were present in very few subjects only in advanced disease. All the subjects were subjected to transthoracic echocardiography and quite a significant number ( $n=110,46.0 \%)$ had $\mathrm{mPAP} \geq 20 \mathrm{mmHg}$, out of which most had mild severity grade $(n=80,33.5 \%)$. The other echocardiographic findings like enlarged right atrium and ventricles, enlarged IVC and reduced TAPSE were significant in moderate to severe group. Likewise, radiographic and ECG parameters showed significant derangement only when the severity increased. The highest prevalence was seen among subjects of non-IPF IIPs, however the number of subjects with this category was so low $(n=5)$ that it cannot be considered significant. In PFT, the FVC value did not show any correlation with the severity of PH. A decline in TLCO with increased severity of pulmonary hypertension was which was expected as it is affected early in the involvement of the vasculature. The $\mathrm{p}$ value was non-significant though. Previously reported prevalence among individual ILDs has ranged from 5 to $50 \%$, and a poor outcome has been reported by all unequivocally [9-14]. All these studies had utilized the older

Figure 2. Sections from HRCT thorax of subjects showing characteristic findings. a) "Head cheese sign" in a patient of HP showing areas of reduced (red arrows), normal (black arrow heads) and increased attenuation (blue arrows). b) Reticulations, traction bronchiectasis (red arrow) and subpleural honeycombing seen in a patient of RA. c) Fibrosis along the bronchovascular bundle (red arrow heads) and cystic areas (black arrow) seen in a patient with stage IV sarcoidosis. d) Peribronchovascular thickening (black arrow) and extensive perilymphatic nodularity in a case of stage II sarcoidosis. e) Peripheral patchy consolidation (black arrows) seen in COP. f) Classic subpleural sparing (black arrowheads) with extensive reticulation and GGO in a case of idiopathic NSIP. g) Subpleural basal reticulations (black arrows) suggestive of probable UIP. h) A coronal section in a case of CPFE with reticulations, traction bronchiectasis, subpleural honeycombing (black arrowheads) with emphysema in the apices (red arrow). 
hemodynamic definition ( $\mathrm{mPAP} \geq 25 \mathrm{mmHg}$ ).

With growing interest and understanding of ILDs in the developing countries, the study of spectrum assumes importance. Better knowledge of prevalent trends and risk factors help in better research investigations and management. Also, it is imperative to screen these subjects for pulmonary hypertension as timely diagnosis and management can help prevent or delay the development of right heart failure.

There were certain limitations to our study. Ours was a single centre study; therefore the findings may not be generalizable to a

Table 4. Association of baseline characteristics and diagnosis.

\begin{tabular}{|c|c|c|c|c|c|c|c|}
\hline Characteristic & HP & Autoimmune ILDs & IPF & Sarcoidosis & Non-IPF IIPs & Others & ANOVA $* / \chi^{2}$ (p-value) \\
\hline Age (years) & $55.8 \pm 11.8$ & $47.3 \pm 12.8$ & $60.7 \pm 9.9$ & $46.2 \pm 12.5$ & $51.0 \pm 20.4$ & $51.2 \pm 16.8$ & $\mathrm{p}<0.001^{*}$ \\
\hline $\begin{array}{l}\text { Gender } \\
\text { Female (\%) } \\
\text { Male (\%) }\end{array}$ & $\begin{array}{l}58.4 \\
41.6\end{array}$ & $\begin{array}{l}80.0 \\
20.0\end{array}$ & $\begin{array}{l}28.9 \\
71.1\end{array}$ & $\begin{array}{l}46.7 \\
53.3\end{array}$ & $\begin{array}{l}80.0 \\
20.0\end{array}$ & $\begin{array}{l}50.0 \\
50.0\end{array}$ & $\mathrm{p}<0.001$ \\
\hline $\begin{array}{l}\text { Smokers } \\
\text { H/o ATT (\%) }\end{array}$ & 26.0 & 14.7 & 18.4 & 26.7 & 20.0 & 14.3 & $\mathrm{p}=0.533$ \\
\hline Duration of symptoms (years) & $2.4 \pm 2.4$ & $4.9 \pm 5.2$ & $1.9 \pm 2.9$ & $2.4 \pm 3.6$ & $3.7 \pm 3.7$ & $2.8 \pm 2.8$ & $\mathrm{p}<0.001^{*}$ \\
\hline 6MWT & $\mathrm{n}=70$ & $\mathrm{n}=73$ & $\mathrm{n}=32$ & $\mathrm{n}=29$ & $\mathrm{n}=3$ & $\mathrm{n}=13$ & \\
\hline 6-minute walk distance (m) & $267.0 \pm 99.1$ & $279.2 \pm 86.3$ & $235.6 \pm 69.0$ & $330.8 \pm 126.3$ & $256.7 \pm 31.3$ & $280.2 \pm 93.3$ & $\mathrm{p}=0.007^{*}$ \\
\hline$\%$ desaturation on 6MWT & $4.2 \pm 4.3$ & $3.7 \pm 2.0$ & $4.7 \pm 2.4$ & $2.0 \pm 2.7$ & $3.3 \pm 1.5$ & $5.2 \pm 2.8$ & $\mathrm{p}=0.008^{*}$ \\
\hline $\mathrm{SpO} 2$ & $93.4 \pm 4.7$ & $96.3 \pm 2.1$ & $92.6 \pm 7.0$ & $95.2 \pm 4.1$ & $89.6 \pm 9.5$ & $94.6 \pm 5.2$ & $\mathrm{p}<0.005^{*}$ \\
\hline Spirometry with TLCO & $\mathrm{n}=69$ & $\mathrm{n}=67$ & $\mathrm{n}=35$ & $\mathrm{n}=28$ & $n=4$ & $n=12$ & \\
\hline FVC (L) & $1.6 \pm 0.6$ & $1.7 \pm 0.5$ & $1.8 \pm 0.5$ & $2.0 \pm 0.6$ & $2.0 \pm 0.3$ & $1.9 \pm 0.7$ & $\mathrm{p}=0.036^{*}$ \\
\hline FVC \% pred. & $57.9 \pm 13.7$ & $61.4 \pm 13.6$ & $59.7 \pm 13.8$ & $66.1 \pm 18.5$ & $72.5 \pm 13.0$ & $61.2 \pm 22.9$ & $\mathrm{p}=0.117^{*}$ \\
\hline Median mMRC & 3.0 & 2.0 & 2.5 & 2.0 & 2.0 & 2.0 & $\mathrm{p}<0.002 \#$ \\
\hline \multicolumn{8}{|c|}{ HRCT distribution } \\
\hline Upper/middle & 68.8 & 4.0 & 0.0 & 86.7 & 0.0 & 50.0 & $\mathrm{p}<0.001$ \\
\hline Lower & 6.5 & 80.0 & 100.0 & 0.0 & 40.0 & 0.0 & \\
\hline Uniform & 24.7 & 16.0 & 0.0 & 13.3 & 60.0 & 50.0 & \\
\hline $\begin{array}{l}\text { Tissue diagnosis } \\
\text { Not done } \\
\text { BAL } \\
\text { FNAC } \\
\text { TBLB } \\
\text { TBNA } \\
\text { TBNA+BAL } \\
\text { mPAP }\end{array}$ & $\begin{array}{c}68.8 \\
29.9 \\
0.0 \\
1.3 \\
0.0 \\
0.0 \\
23.6 \pm 11.1\end{array}$ & $\begin{array}{c}86.7 \\
13.3 \\
0.0 \\
0.0 \\
0.0 \\
0.0 \\
21.3 \pm 9.1\end{array}$ & $\begin{array}{c}73.7 \\
15.8 \\
0.0 \\
0.0 \\
0.0 \\
10.5 \\
21.7 \pm 8.9\end{array}$ & $\begin{array}{c}3.3 \\
0.0 \\
20.0 \\
3.3 \\
16.7 \\
56.7 \\
21.2 \pm 10.7\end{array}$ & $\begin{array}{c}60.0 \\
20.0 \\
0.0 \\
20.0 \\
0.0 \\
0.0 \\
20.6 \pm 6.5\end{array}$ & $\begin{array}{c}50.0 \\
50.0 \\
0.0 \\
0.0 \\
0.0 \\
0.0 \\
25.5 \pm 13.0\end{array}$ & $\mathrm{p}=0.573^{*}$ \\
\hline
\end{tabular}

*ANOVA; \#Kruskal Wallis Test; HP, hypersensitivity pneumonitis; ILD, interstitial lung disease; IPF, idiopathic pulmonary fibrosis; IIP, idiopathic interstitial pneumonias; ANOVA, analysis of variance; ATT, anti-tuberculosis therapy; 6MWT, 6-minute walk test; $\mathrm{SpO}_{2}$, percentage saturation of oxygen; TLCO, transfer factor of the lungs for carbon monoxide; FVC, forced vital capacity; FVC\% pred, percentage predicted value of forced vital capacity; mMRC, modified Medical Research Council; HRCT, high resolution computed tomography; BAL, bronchoalveolar lavage; FNAC, fine needle aspiration cytology; TBLB, trans-bronchial lung biopsy; TBNA, trans-bronchial needle aspiration; mPAP, mean pulmonary artery pressure.

Table 5. ILD wise prevalence and severity of pulmonary hypertension.

\begin{tabular}{|c|c|c|c|c|c|c|c|c|c|}
\hline \multirow[t]{2}{*}{ Diagnosis } & \multirow[t]{2}{*}{ Totaln $=239$} & \multicolumn{2}{|c|}{ No PH $(n=110)$} & \multicolumn{2}{|c|}{ PH $(n=129)$} & \multicolumn{2}{|c|}{ Mild PH $(\mathrm{n}=75)$} & \multicolumn{2}{|c|}{$\begin{array}{c}\text { Moderate }+ \text { severe PH } \\
(\mathrm{n}=28+2=30)\end{array}$} \\
\hline & & No. & $\%$ & No. & $\%$ & No. & $\%$ & No. & $\%$ \\
\hline All ILDs & 239 & 129 & 54.0 & 110 & 46.0 & 80 & 33.5 & 30 & 12.5 \\
\hline HP & 77 & 37 & 48.1 & 40 & 51.9 & 29 & 37.7 & 11 & 14.3 \\
\hline Autoimmune ILDs & 75 & 42 & 56.0 & 33 & 44.0 & 25 & 33.3 & 8 & 10.7 \\
\hline Sarcoidosis & 30 & 19 & 63.3 & 11 & 36.7 & 6 & 20.0 & 5 & 16.7 \\
\hline IPF & 38 & 20 & 52.6 & 18 & 47.4 & 13 & 34.2 & 5 & 13.2 \\
\hline Non-IPF IIPs & 5 & 4 & 80.0 & 1 & 20.0 & 1 & 20.0 & 0 & 0.0 \\
\hline Others & 14 & 7 & 50.0 & 7 & 50.0 & 6 & 42.9 & 1 & 7.1 \\
\hline
\end{tabular}

$\chi^{2}=6.168 ; p=0.801$; ILD, interstitial lung disease; HP, hypersensitivity pneumonitis; IPF, idiopathic pulmonary fibrosis; IIPs, idiopathic interstitial pneumonias. 
larger population. Also, tissue diagnosis could only be established in $34.3 \%$ of patient. Another drawback was that the gold standard investigation to confirm the diagnosis of pulmonary hypertension is right heart catheterization while we screened the subjects with echocardiography. Though not as accurate, it is the best non-invasive screening tool [17-19].

\section{Conclusions}

In conclusion, there is a higher prevalence of hypersensitivity pneumonitis and autoimmune-ILD reporting to our centre. A significant number of subjects had pulmonary hypertension in absence of suggestive clinical features.

Table 6. Association of pulmonary hypertension and 2D echo findings, ECG and chest radiograph findings.

\begin{tabular}{|c|c|c|c|c|c|c|c|c|}
\hline \multirow[t]{2}{*}{ Echocardiography findings } & \multicolumn{2}{|c|}{ No PH $(n=129)$} & \multicolumn{2}{|c|}{ Mild PH $(n=80)$} & \multicolumn{2}{|c|}{ Moderate + severe PH $(n=30)$} & \multicolumn{2}{|c|}{ ANOVA } \\
\hline & Mean & SD & Mean & SD & Mean & SD & $\mathrm{F}$ & p \\
\hline TR velocity (m/s) & 1.15 & 0.28 & 1.63 & 0.69 & 2.53 & 1.06 & 64.863 & $<0.001$ \\
\hline RSVP (mmHg) & 24.84 & 4.06 & 37.50 & 7.73 & 54.70 & 13.55 & 236.263 & $<0.001$ \\
\hline $\operatorname{PAT}(s)$ & 70.00 & 13.39 & 54.95 & 6.30 & 35.85 & 7.42 & 137.854 & $<0.001$ \\
\hline IVC dia (mm) & 13.91 & 1.04 & 16.25 & 2.41 & 21.57 & 1.98 & 244.722 & $<0.001$ \\
\hline RA area (cm2) & 9.05 & 1.74 & 12.88 & 3.71 & 17.40 & 3.63 & 124.899 & $<0.001$ \\
\hline TAPSE (mm) & 2.14 & 0.12 & 2.01 & 0.26 & 1.89 & 0.39 & 19.514 & $<0.001$ \\
\hline FAC $(\%)$ & 38.76 & 5.34 & 40.04 & 6.11 & 39.10 & 6.71 & 1.212 & 0.299 \\
\hline LVEF (\%) & 61.26 & 2.42 & 61.11 & 3.81 & 59.43 & 4.84 & 3.804 & 0.024 \\
\hline & & $\%$ & No. & $\%$ & No. & $\%$ & $\chi^{2}$ & p \\
\hline RA enlargement & 0 & 0.0 & 11 & 13.8 & 20 & 66.7 & 95.895 & $<0.001$ \\
\hline RV enlargement & 0 & 0.0 & 7 & 8.8 & 19 & 63.3 & 101.260 & $<0.001$ \\
\hline Small LT chamber & 0 & 0.0 & 0 & 0.0 & 0 & 0.0 & - & - \\
\hline IV flattening & 0 & 0.0 & 2 & 2.5 & 2 & 6.7 & 7.073 & 0.029 \\
\hline Pericardial effusion & 0 & 0.0 & 0 & 0.0 & 1 & 3.3 & 6.996 & 0.030 \\
\hline $\begin{array}{l}\text { Chest X-ray } \\
\text { Reticulations } \\
\text { Cardiomegaly } \\
\text { Enlarged RPA } \\
\text { Pruning }\end{array}$ & $\begin{array}{c}17 \\
0 \\
0 \\
0\end{array}$ & $\begin{array}{c}13.2 \\
0.0 \\
0.0 \\
0.0\end{array}$ & $\begin{array}{c}10 \\
0 \\
1 \\
0\end{array}$ & $\begin{array}{c}12.5 \\
0.0 \\
1.3 \\
0.0\end{array}$ & $\begin{array}{l}7 \\
9 \\
5 \\
1 \\
\end{array}$ & $\begin{array}{c}23.3 \\
30.0 \\
16.7 \\
3.3\end{array}$ & $\begin{array}{c}2.351 \\
65.153 \\
28.405 \\
6.996\end{array}$ & $\begin{array}{c}0.309 \\
<0.001 \\
<0.001 \\
0.030\end{array}$ \\
\hline ECG & & & & & & & & \\
\hline RVH & 0 & 0.0 & 1 & 1.3 & 17 & 56.7 & 119.041 & $<0.001$ \\
\hline $\mathrm{RAD}$ & 0 & 0.0 & 1 & 1.3 & 21 & 70.0 & 151.805 & $<0.001$ \\
\hline P-pulmonale & 0 & 0.0 & 1 & 1.3 & 13 & 43.3 & 87.508 & $<0.001$ \\
\hline
\end{tabular}

PH, pulmonary hypertension; TR, tricuspid regurgitation; RVSP, right ventricular systolic pressure; PAT, pulmonary acceleration time; IVC dia, inferior vena cava diameter; RA, right atrium; TAPSE, tricuspid annular plane systolic excursion; FAC, fractional area change; LVEF, left ventricular ejection fraction; RV, right ventricle; IVS, inter-ventricle septum; RPA, right pulmonary artery; ECG, electrocardiogram; RVH, right ventricular hypertrophy; RAD, right axis deviation.

Table 7. Comparison with other recent studies (studies done in last 10 years).

\begin{tabular}{|c|c|c|c|c|c|c|c|c|c|c|c|c|}
\hline & Year & $\begin{array}{l}\text { Study } \\
\text { type }\end{array}$ & Country & $\begin{array}{l}\text { Number } \\
\text { f subjects }\end{array}$ & IPF & $\begin{array}{l}\text { Non } \\
\text { IPF IIP }\end{array}$ & Sarcoidosis & $\begin{array}{l}\text { Auto-immune } \\
\text { ILD }\end{array}$ & HP & Occupational & $\begin{array}{l}\text { I Radiation } \\
\text { or drug } \\
\text { induced }\end{array}$ & $\begin{array}{l}\text { Unclas- } \\
\text { sifiable }\end{array}$ \\
\hline Current study & & Prevalent & India & 239 & 15.9 & 2.1 & 12.6 & 31.4 & 32.2 & 2.9 & 0.4 & 0.4 \\
\hline Dhooria et al. [34] & 2018 & Prevalent & India & 803 & 21.2 & 9.2 & 42.2 & 12.7 & 10.7 & 0.9 & 0.7 & 0.9 \\
\hline ILD India Registry [33] & 2016 & Incident & India & 1084 & 13.7 & 12.4 & 7.8 & 13.9 & 47.3 & 3.0 & 0.3 & 0.2 \\
\hline Rajkumar et al. [36] & 2014 & Prevalent & India & 289 & 27.7 & 27.7 & 37.4 & 4.5 & 2.4 & - & - & - \\
\hline Sen et al. [37] & 2010 & Prevalent & India & 274 & - & 46.3 & 22 & 18 & 6.0 & 0.7 & 1.1 & - \\
\hline Karakat-sani et al. [38] & 2009 & Prevalent & Greece & 967 & 19.5 & 10.0 & 34.1 & 12.4 & 2.6 & 2.0 & 1.8 & 8.5 \\
\hline Alhamad et al. [39] & 2013 & Incident & Saudi Arabia & 330 & 23.3 & 9.0 & 20 & 34.8 & 6.4 & - & 1.2 & 1.8 \\
\hline Musellium et al. [40] & 2014 & Incident & Turkey & 2245 & 19.9 & 6.1 & 37.6 & 9.8 & 4.0 & 11.8 & 3.5 & - \\
\hline Hyldgard et al. [41] & 2014 & Incident & Denmark & 431 & 28 & 16 & - & 13 & 7.0 & - & 5.0 & 25 \\
\hline
\end{tabular}

IPF, idiopathic pulmonary fibrosis; IIP, idiopathic interstitial pneumonia; ILD, interstitial lung disease; HP, hypersensitivity pneumonitis. 


\section{References}

1. Selman M. Hypersensitivity pneumonitis. In: Interstitial lung disease, 5th ed. Schwarz M, and King TE Jr, editors. Shelton, CT: People's Medical Publishing House-USA; 2011. pp. 597-625.

2. Raghu G, Collard HR, Egan JJ, et al. An official ATS/ERS/ JRS/ALAT statement: idiopathic pulmonary fibrosis: evidence- based guidelines for diagnosis and management. Am J Respir Crit Care Med 2011;183:788.

3. American Thoracic Society, European Respiratory Society. American Thoracic Society/European Respiratory Society International Multidisciplinary Consensus Classification of the Idiopathic Interstitial Pneumonias. This joint statement of the American Thoracic Society (ATS), and the European Respiratory Society (ERS) was adopted by the ATS board of directors, June 2001 and by the ERS Executive Committee, June 2001. Am J Respir Crit Care Med 2002;165:277.

4. King TE Jr, Pardo A, Selman M. Idiopathic pulmonary fibrosis. Lancet 2011;378:1949.

5. Travis WD, Hunninghake G, King TE Jr, et al. Idiopathic nonspecific interstitial pneumonia: report of an American Thoracic Society project. Am J Respir Crit Care Med 2008;177:1338.

6. Bradley B, Branley HM, Egan JJ, et al. Interstitial lung disease guideline: the British Thoracic Society in collaboration with the Thoracic Society of Australia and New Zealand and the Irish Thoracic Society. Thorax 2008;63:v1-58.

7. Cottin V, Hirani NA, Hotchkin DL, et al. Presentation, diagnosis and clinical course of the spectrum of progressive-fibrosing interstitial lung diseases. Eur Respir Rev 2018;27:180076.

8. Singh S, Sharma BB, Bairwa M, et al. Management of interstitial lung diseases: A consensus statement of the Indian Chest Society (ICS) and National College of Chest Physician (NCCP). Lung India 2020;37:359-78.

9. Behr J, Ryu J. H. Pulmonary hypertension in interstitial lung disease. Eur Respir J 2008;31:1357-67.

10. Maimon N, Salz L, Shershevsky Y, et al. Sarcoidosis-associated pulmonary hypertension in subjects with near-normal lung function. Int J Tuberc Lung Dis 2013;17:406-11.

11. Oliveira RK, Pereira CA, Ramos RP, et al. A haemodynamic study of pulmonary hypertension in chronic hypersensitivity pneumonitis. Eur Respir J 2014;44:415-24.

12. Koschel DS, Cardoso C, Wiedemann B, et al. Pulmonary hypertension in chronic hypersensitivity pneumonitis. Lung 2012;190:295-302.

13. Yan W, Peng LY, Ban CJ, et al. Incidence and clinical characteristics of pulmonary hypertension in subjects with idiopathic pulmonary fibrosis. Chin Med J (Engl) 2015;128:896-901.

14. Cottin V, Le Pavec J, Prévot G, et al. Pulmonary hypertension in subjects with combined pulmonary fibrosis and emphysema syndrome. Eur Respir J 2010;35:105-11.

15. Hatano S, Strasser T, World Health Organization. Primary pulmonary hypertension: report on a WHO meeting, Geneva, 1517 October 1973. World Health Organization; 1975.

16. Simonneau G, Montani D, Celermajer DS, et al. Haemodynamic definitions and updated clinical classification of pulmonary hypertension. Eur Respir J 2019;53:1801913.

17. Haddad F, Zamanian R, Beraud A-S, et al. A novel non-invasive method of estimating pulmonary vascular resistance in subjects with pulmonary arterial hypertension. J Am Soc Echocardiogr 2009;22:523-9.

18. Currie PJ. Seward JB, Chan KL, et al. Continuous wave Doppler determination of right ventricular pressure: a simulta- neous Doppler-catheterization study in 127 subjects. J Am Coll Cardiol 1985;6:750-6.

19. Amsallem M, Sternbach JM, Adigopula S, et al. Addressing the controversy of estimating pulmonary arterial pressure by echocardiography. J Am Soc Echocardiogr 2016;29:93-102.

20. Saleem SM. Modified Kuppuswamy scale for the year 2018. Papirex Indian J Res 2018;7:217-18.

21. Jones PW, Adamek L, Nadeau G et al. Comparisons of health status scores with MRC grades in COPD: implications for the GOLD 2011 classification. Eur Respir J 2013;42:647-54.

22. ATS Committee on Proficiency Standards for Clinical Pulmonary Function Laboratories. ATS statement: guidelines for the six-minute walk test. Am J Respir Crit Care Med 2002;166:111-7.

23. Guidelines for the measurement of respiratory function. Recommendations of the British Thoracic Society and the Association of Respiratory Technicians and Physiologists. Respir Med 1994;88:165-94.

24. Moore VC. Spirometry: step by step. Breathe 2012;8:232-40.

25. ATS/ERS Task Force. Standardisation of Lung Fuction testing. Interpretative strategies for lung function tests. Eur Respir J 2005;26:948-58.

26. Global Initiative for Chronic Obstructive Lung Disease. Global Strategy for the Diagnosis, Management and Prevention of COPD, 2018. Accessed: July 17, 2018. Available from: https://goldcopd.org/gold-reports/

27. Raghu G, Remy-Jardin M, Myers JL, et al. Diagnosis of idiopathic pulmonary fibrosis- An official ATS/ERS/JRS/ALAT clinical practice guideline. Am J Respir Crit Care Med 2018;198:563-80.

28. Travis WD, Costabel U, Hansell DM, et al. An official American Thoracic Society/European Respiratory Society statement: Update of the international multidisciplinary classification of the idiopathic interstitial pneumonias. Am J Respir Crit Care Med 2013;188:733-48.

29. Fischer A, Antoniou KM, Brown KK, et al. An official European Respiratory Society/American Thoracic Society research statement: interstitial pneumonia with autoimmune features. Eur Respir J 2015;46:976-87.

30. Rudski LG, Lai WW, Afilalo J, et al. Guidelines for the echocardiographic assessment of the right heart in adults: A report from the American Society of Echocardiography. J Am Soc Echocardiogr 2010;23:685-713.

31. Mahan G, Dabestani A, Gardin J, et al. Estimation of pulmonary artery pressure by pulsed Doppler echocardiography. Circulation 1983;68:367.

32. Life in the Fastlane [Internet]. Pulmonary Hypertension Echocardiography. Accessed: 1st July, 2020. Available from: https://itfl.com/pulmonary-hypertension-echocardiography/

33. Singh S, Collins BF, Sharma BB, et al. Interstitial lung disease in India. Results of a prospective registry. Am J Respir Crit Care Med 2017;195:801-13.

34. Dhooria S, Agarwal R, Sehgal IS, et al. Spectrum of interstitial lung diseases at a tertiary center in a developing country: A study of 803 subjects. PLoS One 2018;13:e0191938.

35. Akhter N, Rizvi NA. Interstitial lung diseases misdiagnosed as tuberculosis. Pak J Med Sci 2018;34:338-41.

36. Kumar R, Gupta N, Goel N. Spectrum of interstitial lung disease at a tertiary care centre in India. Pneumonol Alergol Pol 2014;82:218-26.

37. Sen T, Udwadia ZF. Retrospective study of interstitial lung disease in a tertiary care centre in India. Indian J Chest Dis Allied Sci 2010;52:207-11. 
38. Karakatsani A, Papakosta D, Rapti A, et al. Epidemiology of interstitial lung diseases in Greece. Respir Med 2009;103:1122-9.

39. Alhamad EH. Interstitial lung diseases in Saudi Arabia: A single-center study. Ann Thorac Med 2013;8:33-7.

40. Musellim B, Okumus G, Uzaslan E, et al. Epidemiology and distribution of interstitial lung diseases in Turkey. Clin Respir J 2014;8:55-62.

41. Hyldgaard C, Hilberg O, Muller A, Bendstrup E. A cohort study of interstitial lung diseases in central Denmark. Respir Med 2014;108: 93-9. 